\title{
OPEN Evaluation of the antibacterial effects and mechanism of Plantaricin 149 from Lactobacillus plantarum NRIC 149 on the peri-implantitis pathogens
}

\author{
Xiaolong Lin, Jiajia Xu, Zhiwei Shi, Yuedan Xu, Tao Fu, Ling Zhang ${ }^{\varpi}$ \&uming $\mathrm{He}^{\bowtie}$
}

Peri-implantitis is a common reversible disease after tooth implantation, caused by a variety of pathogenic microorganisms. Based on non-surgical or surgical treatment principles, supplementation by local or systemic drugs might enhance treatment efficacy. Porphyromonas gingivalis (Pg) (ATCC $33,277)$ and Prevotella intermedius (Pi) (ATCC 25,611) were used as test strains. The effects of PIn 149 on the biofilm formation and growth of four periodontal pathogens were evaluated by RT-PCR, fluorescence microscopy, and scanning electron microscopy. The antibacterial mechanism was tested by the patch-clamp technique. The cytotoxicity of PIn $149(125 \mu \mathrm{g} / \mathrm{ml})$ to bone marrow stromal cell (BMSC) was assessed using an MTT assay. PIn 149 exhibited significant inhibitory effects on Pg and Pi $(P<0.05)$, with significant differences in the biofilm images of fluorescence microscope and scanning electron microscope $(P<0.05)$. Pln 149 could change the sodium channel currents and exerted no cytotoxicity on bone marrow stromal cell. PIn 149 could inhibit the biofilm formation and growth of periodontal pathogens. Considering the absence of antimicrobial resistance and cytotoxicity, we suggest that the PIn 149 from Lactobacillus plantarum 149 might be a promising option for managing peri-implantitis.

Peri-implantitis is a common reversible disease after tooth implantation, which occurs in oral soft tissues around the implant. Peri-implantitis is caused by a variety of pathogenic microorganisms and often requires treatment in various ways ${ }^{1}$. Non-surgical or surgical treatment, supplemented by local or systemic drugs, might improve treatment efficacy ${ }^{2}$. Removing and controlling biofilms on the implant are the key to the treatment of the inflammation. However, due to differences between implant materials and natural tooth structures, it is more difficult to remove dental plaque from implant surfaces ${ }^{3}$. Therefore, the auxiliary role of drug therapy becomes more important in the treatment of peri-implantitis.

Antibacterial peptides are small peptides, $<100$ amino acids long, with broad-spectrum antibiotic properties. They are widely available in nature, both in plants and animals ${ }^{4}$. Lactobacillus plantarum is a probiotic that can produce organic acid, hydrogen peroxide, and diacetyl; it can also produce a small molecular protein with bacteriostatic activity, called bacteriocin ${ }^{5}$. Compared with traditional antibiotics, the antibacterial peptides have more advantages, such as no residues, no resistance, and easy protease degradation in the human gut, and have become a new option for treating infectious diseases ${ }^{6}$. Plantaricin 149 (Pln149), is a cationic antimicrobial peptide produced by Lactobacillus plantarum NRIC 149 that has been identified as a bacteriocin with a molecule weight of $2.2 \mathrm{kDa}$ and was also heat-stable and active at pHs ranging from 4.0-7.0. Earlier studies have shown that Pln 149 exerts a strong antibacterial effect on common clinical pathogens ${ }^{7}$. Our previous study also showed that the

Department of Prosthodontics, Stomatology Hospital, School of Stomatology, Zhejiang University School of Medicine, Zhejiang Provincial Clinical Research Center for Oral Diseases, Key Laboratory of Oral Biomedical Research of Zhejiang Province, Cancer Center of Zhejiang University, Hangzhou 310006, China. ${ }^{\bowtie}$ email: jorlinzhang@zju. edu.cn; hfm@zju.edu.cn 


\begin{tabular}{|l|l|l|l|}
\hline Species & Sequence( (' $^{\prime}$ to $\mathbf{3}^{\prime}$ ) & Target gene & Amplicon size(bp) \\
\hline P.gingival & $\begin{array}{l}\text { F:GGAAGAGAAGACCGTAGCACAAGGA } \\
\text { R:GAGTAGGCGAAACGTCCATCAGGTC }\end{array}$ & $r p o B$ & 143 \\
\hline P.intermedia & $\begin{array}{l}\text { F:CCACATATGGCATCTGACGTG } \\
\text { R:TCAATCTGCACGCTACTTGG }\end{array}$ & $r p o B$ & 117 \\
\hline Total Bacteria & $\begin{array}{l}\text { F:CCATGAAGTCGGAATCGCTAG } \\
\text { R:GCTTGACGGGCGGTGT }\end{array}$ & 165 rRNA & 89 \\
\hline
\end{tabular}

Table 1. qPCR Primers used in this study.

peptide secreted by L. plantarum exerted strong inhibitory effects on S. mutans and P. gingivalis. Therefore, the use of Pln 149 from Lactobacillus plantarum 149 in the treatment of peri-implantitis seems relevant.

In this study, we aim to study the antibacterial effect of Pln 149 on the peri-implantitis pathogen in vitro and test the antimicrobial resistance and cytotoxicity. For that, we determined the bacterial count in the biofilm and used confocal laser scanning microscopy and transmission electron microscopy to verify the effects of Pln 149 in the treatment of peri-implantitis. Meanwhile, the antimicrobial resistance on Staphylococcus aureus and cytotoxicity on osteoblasts were tested to verify the clinical value of Pln 149.

\section{Methods}

Strains and culture conditions. Porphyromonas gingivalis (Pg) (ATCC 33,277), Staphylococcus aureus (ATCC 29,213), and Prevotella intermedius (Pi) (ATCC 25,611) were purchased from ATCC. Cultures of Pg and Pi were grown overnight in brain heart infusion broth (BHI) (Difco, USA) under anaerobic conditions $\left(80 \% \mathrm{~N}_{2}\right.$, $10 \% \mathrm{CO}_{2}$, and $10 \% \mathrm{H}_{2}$ ) at $37^{\circ} \mathrm{C}$ in an anaerobic chamber. S. aureus was grown overnight in $\mathrm{BHI}$ in a microaerophilic environment $\left(5 \% \mathrm{CO}_{2}\right)$. Then, the bacterial suspensions were centrifuged at $2000 \mathrm{rpm} / \mathrm{min}$ for $5 \mathrm{~min}$, and the final concentrations of the cultures were adjusted to $0.5 \times 10^{5} \mathrm{CFU} / \mathrm{mL}$ using a spectrophotometer.

Peptide. Pln 149 (YSLQM GATAI KQVKK LFKKK GG) was synthesized by Shanghai Apeptide Co. Ltd (Shanghai, China). The peptide was purified by high-performance liquid chromatography, and its identity was verified by SDS-PAGE. The purity of Pln 149 (>95\%) and mass were confirmed by electrospray ionization mass spectrometry.

Minimum inhibitory and minimum bactericidal concentration. The minimum inhibitory (MIC) and minimum bactericidal (MBC) concentrations of Pln 149 were determined for all the strains using a modified version of the Clinical Laboratory and Standard Institute (CLSI) broth microdilution method as described previously $^{8}$. Bacterial suspensions were prepared to a final concentration of $5 \times 10^{5} \mathrm{CFU} / \mathrm{mL}$ in BHI and added to wells in a sterile 96-well microtiter plate containing two-fold dilutions of Pln 149. The blood plate was incubated at $37^{\circ} \mathrm{C}$ for $24 \mathrm{~h}$. The MIC was set as the lowest concentration of peptides that reduced bacterial growth by $\geq 90 \%$, while the MBC was set as the lowest concentration of peptides that reduced bacterial growth by $>99.99 \%$ after the enumeration of viable bacteria by plate counts compared to bacteria grown without antimicrobial peptides.

Biofilm formation. Biofilm formation was assessed using a previously published method ${ }^{9}$. Pg and Pi culture were incubated in BHI broth and grown under an anaerobic aerophilic condition for $24 \mathrm{~h}$ at $37^{\circ} \mathrm{C}$. The cells were washed three times with a saline solution and then adjusted with saline to $0.5 \times 10^{5} \mathrm{CFU} / \mathrm{mL}$. Individual sterile petri dishes were filled with $9.9 \mathrm{ml}$ BHI broth by a concentration of $100 \mu \mathrm{g} / \mathrm{ml}$ Pln 149 . Then a sterile saliva-coated titanium plate was added to each one and individual or mixed $100 \mu \mathrm{L} \mathrm{Pg}$ and Pi suspensions were mixed in the dishes. As negative and positive controls, PBS and Chlorhexidine (CHX) suspensions $(100 \mu \mathrm{g} / \mathrm{ml})$ were used, respectively. All the Petri titanium plates were incubated in anaerobic conditions $\left(80 \% \mathrm{~N}_{2}, 10 \% \mathrm{CO}_{2}\right.$, and $10 \% \mathrm{H}_{2}$ ) at $37^{\circ} \mathrm{C}$ in an anaerobic chamber.

The analysis of biofilm formation on titanium by a quantitative real-time polymerase chain reaction. During the $24 \mathrm{~h}$ of biofilm formation, the titanium pieces were placed in $1 \mathrm{~mL}$ of PBS buffer and vortexed for $90 \mathrm{~s}$. The quantitative real-time polymerase chain reaction was conducted by the method of Choi $\mathrm{EJ}^{10}$. The culture was then diluted in PBS to $10^{-3}$. Finally, bacterial RNA from $100 \mu$ of the suspension was prepared and analyzed by previously described methods. Real-time PCR was performed in triplicate in a $10 \mu \mathrm{l}$ reaction volume containing $1 \times$ SYBR Green Master Mix (DBI, China), $100 \mathrm{nM}$ specific primer, and $50 \mathrm{ng}$ template DNA on an ABI PRISM 7900HT system (Applied Biosystems Inc, USA) in 384-well PCR plates, the qPCR Primers used in this study are shown in Table 1.

Laser confocal microscopy. After a total of $24 \mathrm{~h}$ of biofilm formation, titanium was washed with $10 \mathrm{~mL}$ of phosphate-buffered saline (PBS) to remove unattached cells. The titanium were then fixed with $2.5 \%$ glutaraldehyde at $4{ }^{\circ} \mathrm{C}$ for $1 \mathrm{~h}$. After fixation, the titanium were stained with a $0.01 \%$ acridine orange solution and washed three times with PBS. Any resulting biofilm was observed under a Zeiss LSM 710 laser (Zeiss, Germany) confocal microscope equipped with an argon laser with an excitation wavelength of $488 \mathrm{~nm}$. All the images were captured and saved using Zeiss ZEN 2010 software (version 6.0; Zeiss, Germany) ${ }^{11}$. 


\begin{tabular}{|l|l|l|l|l|l|l|l|l|l|}
\hline & & & \multicolumn{2}{|l|}{ P.gingival } & \multicolumn{2}{l|}{ P.intermedia } & \multicolumn{2}{l|}{ S.aureus } \\
\cline { 6 - 10 } Antibiotics & Sequence & MW & MIC & MBC & MIC & MBC & MIC & MBC \\
\hline Pln149 & YSLQMGATAIKQVKKLFKKK GG & 2130 & 125 & 125 & 100 & 100 & 78 & 78 \\
\hline Cefuroxime & & 424 & 30 & 15 & 20 & 20 & 80 & 80 \\
\hline
\end{tabular}

Table 2. Primary structure, molecular weight, MIC and MBC of Pln149 on P.gingival, P.intermedia and S.aureus; and MIC and MBC of Cefuroxime on S.aureus. Values are given in $\mu \mathrm{g} / \mathrm{ml}$.

Electron microscopy. Scanning electron microscopy (SEM) was used by previous methods to visualize the damage to biofilm caused by Pln $149^{12}$. The Pg and Pi mixed biofilms were formed on titanium and washed with PBS. The biofilms were then treated with Pln 149 for $24 \mathrm{~h}$, followed by fixation in $2.5 \%$ glutaraldehyde in $0.1-\mathrm{M}$ phosphate buffer at $\mathrm{pH}$ 7.3. The dried samples were examined under the scanning electron microscope (NNS450, FEI Company). Digital images were taken under the 5000 magnified visual field at 5kv.

Planar lipid bilayer preparation and electrical measurements. The whole-cell patch-clamp technique was conducted by the methods of Ghaderi ${ }^{13}$. The whole-cell patch-clamp technique was employed at room temperature $\left(23-25^{\circ} \mathrm{C}\right)$ to measure ionic currents. Pipettes were pulled from glass capillaries that exhibited a resistance of 1-3 M $\Omega$ when filled with the pipette solution. The currents were measured in two sets of solutions, one designed to isolate the $\mathrm{Na}^{+}$current and the other to measure $\mathrm{K}^{+}$currents, as described below.

The primary cultured mouse dorsal root ganglion neurons (DRGs) were isolated and cultured according to the standard method. After $24 \mathrm{~h}$, the whole-cell voltage-gated sodium and potassium currents were recorded and plotted the current-voltage curves. When sodium and potassium channel currents were recorded, standard extracellular fluid ( $\mathrm{NaCl} 140 \mathrm{mmol} / \mathrm{L}, \mathrm{KCl} 15 \mathrm{mmol} / \mathrm{L}, \mathrm{CaCl}_{2} 2 \mathrm{mmol} / \mathrm{L}, \mathrm{MgCl}_{2} 1 \mathrm{mmol} / \mathrm{L}, \mathrm{HEPES} 10 \mathrm{mmol} / \mathrm{L}$, Glucose $10 \mathrm{mmol} / \mathrm{L}$ ) and electrode inner liquid (K-gluconate $140 \mathrm{mmol} / \mathrm{L}, \mathrm{KCl} 5 \mathrm{mmol} / \mathrm{L}, \mathrm{MgCl}_{2} 2 \mathrm{mmol} / \mathrm{L}$, EGTA $10 \mathrm{mmol} / \mathrm{L}, \mathrm{K} 2-\mathrm{ATP} 2 \mathrm{mmol} / \mathrm{L}$, GTP $0.1 \mathrm{mmol} / \mathrm{L}$ ), The cells were clamped at $-80 \mathrm{mV}$ and given a step voltage of $100 \mathrm{~ms},+10 \mathrm{mV}$, and gradually depolarised from $-80 \mathrm{mV}$ to $+60 \mathrm{mV}$. Statistical values are given as means $\pm 95 \%$ confidence limits.

MTT assay. The cytotoxicity of Pln $149(125 \mu \mathrm{g} / \mathrm{ml})$ to bone marrow stromal cell (BMSC) was assessed using an MTT cell proliferation kit (Roche Applied Science) ${ }^{14}$. The BMSC were incubated at $37^{\circ} \mathrm{C}$ under $5 \% \mathrm{CO}_{2}$ for 1 , 2 , and 3 days after cell inoculation as described previously. A 50-mL volume of MTT working solution was added to each well, and the mixture was incubated for another $4 \mathrm{~h}$. Purple crystal formazan was observed around cells at $\times 40$ magnification under a microscope. The cell medium was carefully removed, and then $100 \mathrm{~mL}$ of dimethyl sulfoxide was added to each well to dissolve formazan. After $15 \mathrm{~min}$ of incubation at $37^{\circ} \mathrm{C}$ to completely dissolve formazan, the absorbance at $490 \mathrm{~nm}$ was measured on an enzyme-linked immunosorbent assay (ELISA) plate reader, and the results were expressed as optical density (OD) values.

Drug resistance test. S. aureus was grown overnight in $\mathrm{BHI}$ in a microaerophilic environment $\left(5 \% \mathrm{CO}_{2}\right)$. The Disc diffusion test was used for the common antibiotics sensitivity test of Pln $149(30 \mu \mathrm{g})$ and Cefuroxime $(30 \mu \mathrm{g})^{15}$. Then $S$. aureus was added in sublethal concentrations of Pln 149 and Cefuroxime (both $70 \mu \mathrm{g} / \mathrm{ml}$ ) prepared by the BHI method in a microaerophilic environment for $12 \mathrm{~h}$. The Disc diffusion test was tested after $0,12,24$ and 48 times of culturing in the methods mentioned above. The inhibition zone diameters were determined with filter paper.

Statistical analysis. All tests were repeated three times. The data were analyzed using GraphPad Prism 5.0. One-way ANOVA and Tukey multiple comparison tests were used for comparisons between different treatments. A P-value $<0.05$ was considered statistically significant.

\section{Results}

Growth and biofilm inhibition of PIn 149 on Pg and Pi. Table 2 presents the results of MIC and MBC of Pln 149 on Pg and Pi. Pln 149 exerted strong antibacterial effects on biofilm formation on individual or mixed $\mathrm{Pg}$ and Pi. Figure 1 presents the fluorescence microscope images the IOD of biofim, Table 3 presents the results of RT-PCR of viable cells of P.gingival and P.intermedia on titanium plate, Pln 149 reduced the biofilm formation on individual or mixed Pg and Pi significantly $(\mathrm{P}<0.05$, Fig. 1, Table 3$)$. Figure 2 presents the images of scanning electron microscope (SEM), which showed the cells of P.gingival and P.intermedia on titanium plate holes in Pln 149 groups were comparatively rare, the images were in constant with the RT-PCR results.

Whole cell patch clamp of PIn 149. Whole cell patch clamp of Pln 149 were conducted at a final concentration of $125 \mu \mathrm{g} / \mathrm{ml}$ of Pln 149. Figure 3 presents the results. Pln 149 enhanced the sodium current at $-20 \mathrm{mM}$ voltages $(\mathrm{P}<0.05$, Fig. 3). While the Pln 149 on the potassium curve moved to the left, the highest response changed slightly, with no significant difference (Fig. 3).

MTT experiment analysis. As shown in Fig. 4A, after $24 \mathrm{~h}, 48 \mathrm{~h}$ and $72 \mathrm{~h}$ culture, the cell morphology of BMSC fluorescence stained by DAPI and F-actin showed no obvious changes. Meanwhile, there was no signifi- 
A

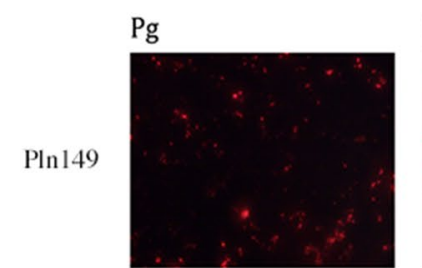

$\mathrm{Pi}$
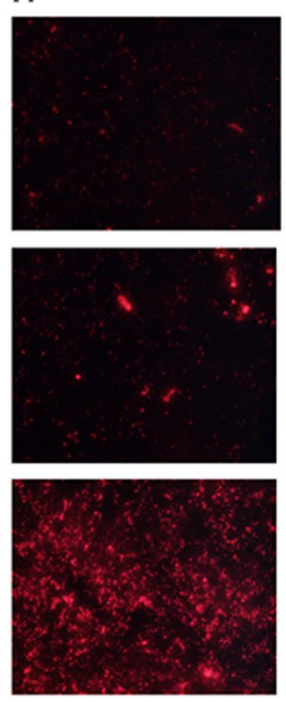

$\mathrm{Pg}+\mathrm{Pi}$
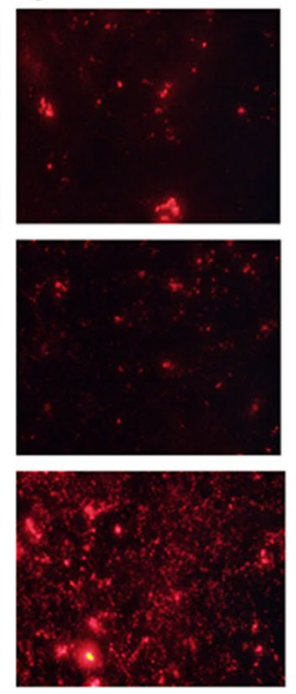

B

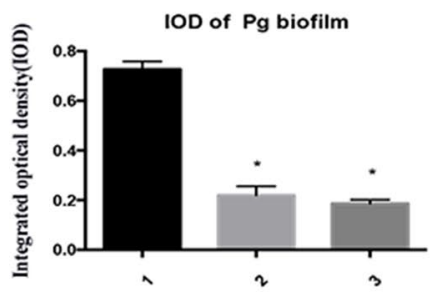

IOD of Pi biofilm
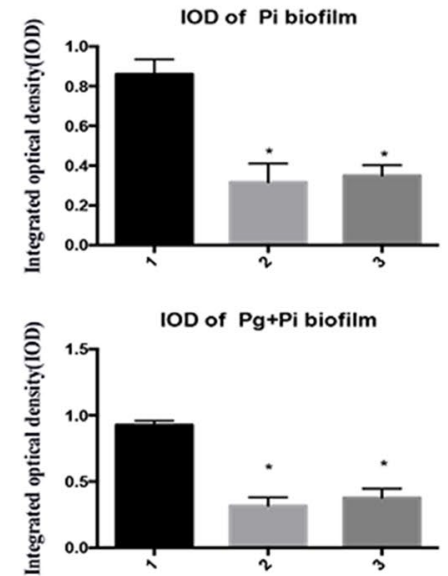

Figure 1. (A) Microscopic fluorescence images of biofilms on titanium-plate in blank control, Chlorhexidine (CHX, $100 \mu \mathrm{g} / \mathrm{ml})$-treated and Pln149-treated groups $(100 \mu \mathrm{g} / \mathrm{ml})$ after $24 \mathrm{~h}$; (B) The integrated optical density (IOD) of biofilms on titanium-plate in blank control, CHX-treated $(100 \mu \mathrm{g} / \mathrm{ml})$ and Pln149-treated $(100 \mu \mathrm{g} / \mathrm{ml})$ groups after $24 \mathrm{~h}\left(\right.$ mean $\left.\pm \mathrm{SD},{ }^{*} \mathrm{P}<0.05\right)$.

\begin{tabular}{|l|l|l|l|}
\hline & Pg & Pi & Pg + Pi \\
\hline Pln149 & $1.21 \pm 0.28 \times 10^{7} / \mathrm{ml}^{*}$ & $0.98 \pm 0.33 \times 10^{7} / \mathrm{ml}^{*}$ & $2.01 \pm 0.42 \times 10^{7} / \mathrm{ml}^{*}$ \\
\hline Chlorhexidine & $1.01 \pm 0.43 \times 10^{7} / \mathrm{ml}^{*}$ & $0.78 \pm 0.29 \times 10^{7} / \mathrm{ml}^{*}$ & $0.95 \pm 0.26 \times 10^{7} / \mathrm{ml}^{*}$ \\
\hline Control & $3.43 \pm 0-89 \times 10^{7} / \mathrm{ml}$ & $3.39 \pm 1.01 \times 10^{7} / \mathrm{ml}$ & $7.54 \pm 2.78 \times 10^{7} / \mathrm{ml}$ \\
\hline
\end{tabular}

Table 3. RT-PCR of viable cells of P.gingival and P.intermedia on titanium plate(, Data are expressed as the mean $\pm S D ; *<0.05)$.

Pln149

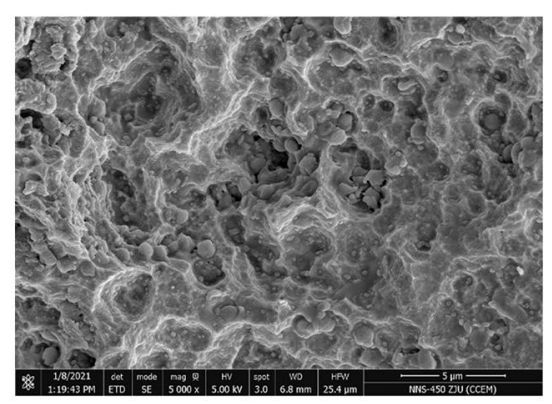

CHX

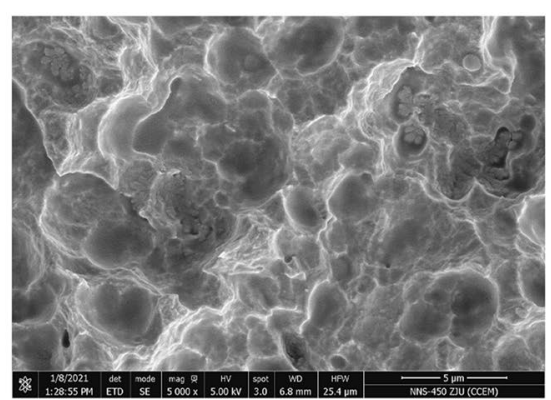

Control

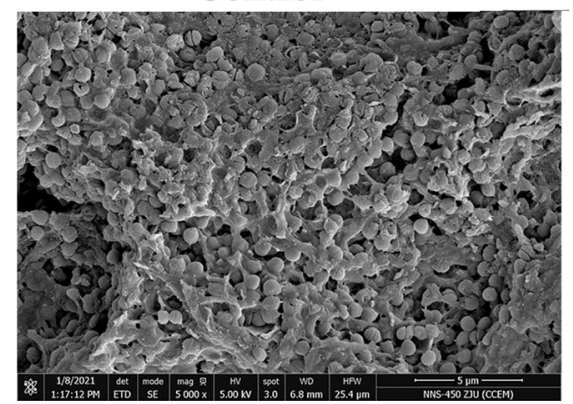

Figure 2. Scanning electron microscope of Pg and Pi mixed biofilms on titanium-plate in blank control, Chlorhexidine $(\mathrm{CHX})$-treated $(100 \mu \mathrm{g} / \mathrm{ml})$ and Pln149-treated $(100 \mu \mathrm{g} / \mathrm{ml})$ groups after $24 \mathrm{~h}$.

cant difference in cell viability or proliferation between the Pln 149 and control groups throughout the $24 \mathrm{~h}, 48 \mathrm{~h}$ and $72 \mathrm{~h}$ culture period (Fig. 4B).

Drug resistance test. As shown in Fig. 5, after 12, 24, and 48 times of culture, the inhibition zone diameters of Pln 149 showed no significant differences compared with original S. aureus. However, the inhibition zone diameters of Cefuroxime began to decrease after 24 times of culture, and with almost no antibacterial effects after 24 times of culture (Table 4). 
A

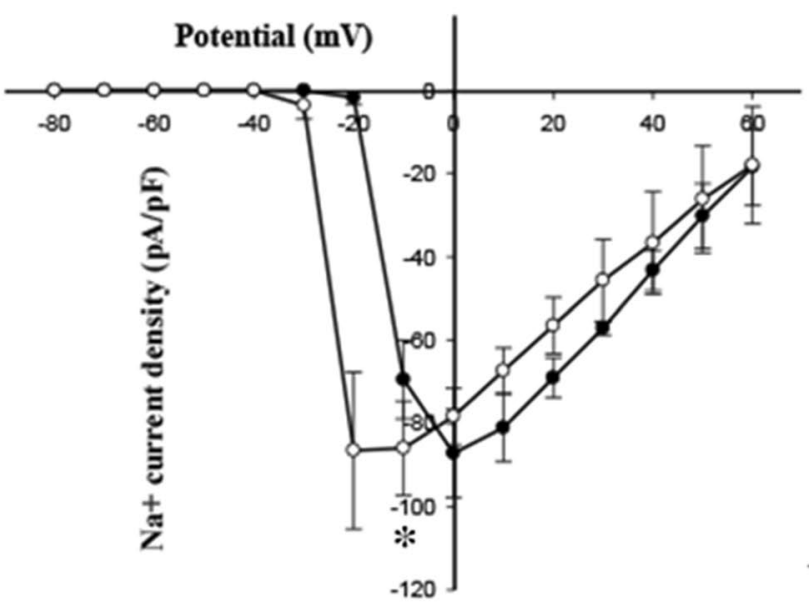

B

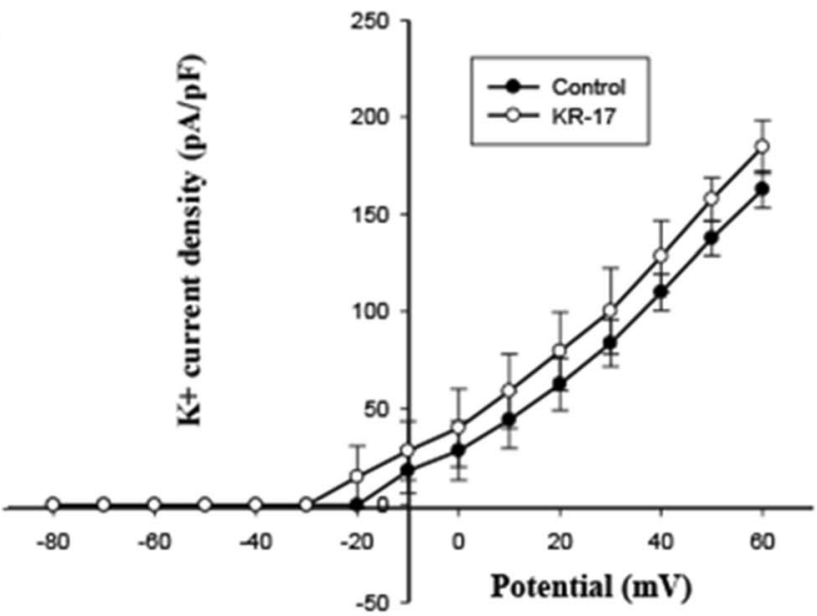

Figure 3. I-V curve of sodium (A) and potassium channel (B) currents on dorsal root ganglion neurons (DRGs) in control groups and Pln149-treated groups.
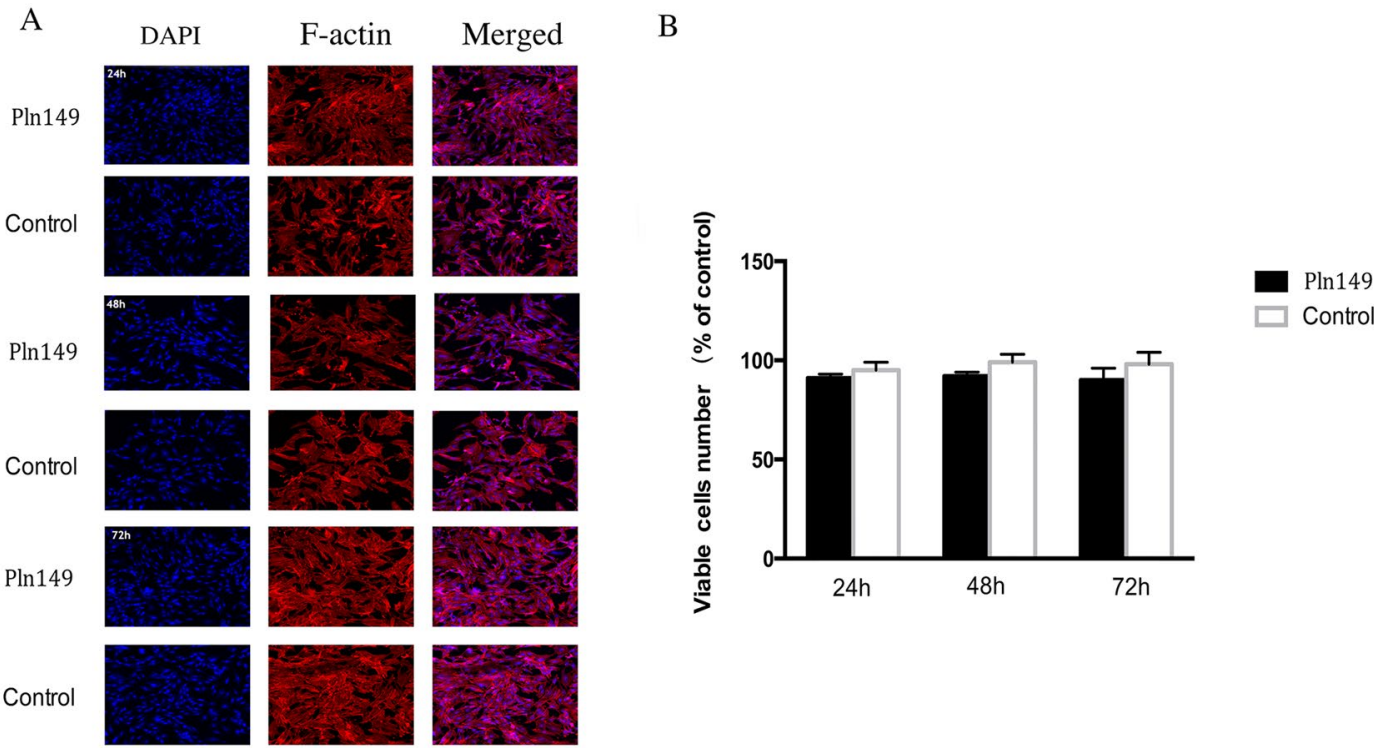

Figure 4. (A) Microscopic fluorescence images showing no morphological changes of the primary bone marrow stromal cell (BMSC) and BMSC cells treated with Pln 149 for $24 \mathrm{~h}, 48 \mathrm{~h}$, and $72 \mathrm{~h}$. (B) The BMSC cell viability was measured by MTT assay. Values are expressed as mean and SD. ${ }^{*} \mathrm{p}<0.05$ compared with the control group.

\section{Discussion}

Peri-implant disease is among the most important reasons for the failure of dental implants. Recent research showed that peri-implant mucositis and peri-implantitis (PI) prevalence rates were $64.6 \%$ and $8.9 \%$, respectively ${ }^{16}$. Many researchers believe that bacteria can be transferred from the periodontitis and periarthritis areas to implant-surrounding tissues; therefore, microorganisms associated with PI are similar to those inducing periodontal and periapical diseases ${ }^{17}$. Compared with using common treatments (including plaque control, mechanical debridement, antibiotics, physiological saline solution, hydrogen peroxide flushing, surgical treatment, and laser treatment), the local or systemic release of antibiotics can eliminate periodontopathogens to a large extent to promote the healing of tissues surrounding implants with $\mathrm{PI}^{18}$. Since local or systemic delivery of antibiotics plays an essential role in the treatment of PI, finding effective antibiotics seems crucial. Pg and Pi are extremely 
A

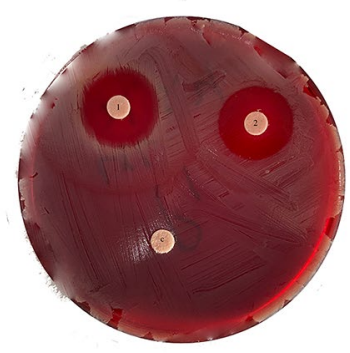

C

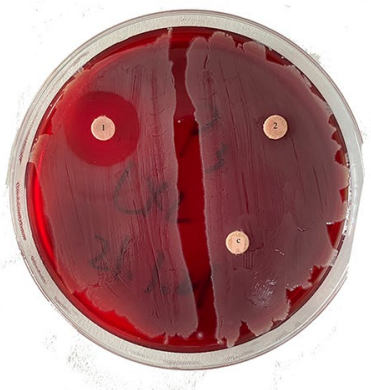

B

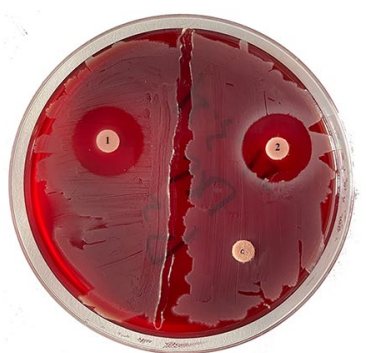

D

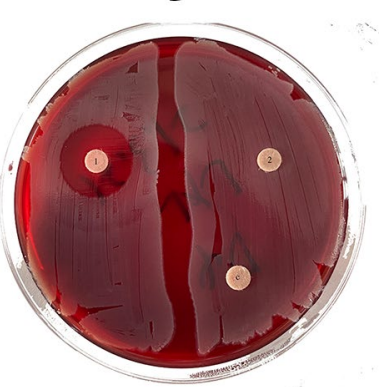

Figure 5. S. aureus after 12, 24, 48 times culture with sublethal concentrations of Cefuroxime and Pln 149 using a $0.5 \mathrm{McF}$ arland inoculum that were characterized by 100ug Cefuroxime and Pln 149 disk diffusion test (A original strain; B S. aureus after 12 times culture; C S. aureus after 24 times culture; D S. aureus after 48 times culture; 1: Pln149 groups; 2: Cefuroxime groups; c: control groups).

\begin{tabular}{|l|l|l|l|l|}
\hline Antibiotics & $\mathbf{0}$ & $\mathbf{1 2}$ & $\mathbf{2 4}$ & $\mathbf{4 8}$ \\
\hline Pln149 & $24.09 \pm 2.37$ & $23.78 \pm 2.98$ & $23.09 \pm 2.18$ & $23.01 \pm 1.28$ \\
\hline Cefuroxime & $21.45 \pm 3.98$ & $18.78 \pm 3.09$ & $6.93 \pm 0.78$ & 0 \\
\hline
\end{tabular}

Table 4. Antimicrobial activity of $\operatorname{Pln} 149(30 \mu \mathrm{g})$ and Cefuroxime (30 $\mu \mathrm{g})$ against S.aureus (after 12,24,and 48 times culture under $70 \mu \mathrm{g} / \mathrm{ml}$ sublethal concentrations of Pln 149 and Cefuroxime) using paper disk diffusion method. Diameter of inhibitory zone $<7 \mathrm{~mm}$ considered as no antimicrobial activity. Values are mean diameter of inhibitory zone $(\mathrm{mm}) \pm \mathrm{SD}$ of five replicates.

susceptible to grow on the rough surface of the implant ${ }^{19}$, our present SEM study showed that Pln 149 could significantly reduce the number of Pg and Pi on titanium surface, consistent with previous studies ${ }^{20}$.

Many studies have already compared the biofilm microbial proteomics in PI and health around implants or periodontitis. Compared with periodontitis samples or healthy implants, the biofilm in PI-surrounding tissues mainly comprises $\mathrm{Pg}$ and $\mathrm{Pi}^{21}$. However, PI biofilm might be worse than the surrounding tissue of periodontitis because PI has a broader spectrum of microorganisms. According to the present study, antibiotics as adjunctive drugs of PI routine treatment can promote the resolution of inflammation in tissues surrounding implants ${ }^{22}$. Mechanical debridement and antibiotic therapy could eliminate a significant number of bacteria in biofilms. However, due to the surface characteristics of various implant systems and differences between the forms and surface treatments, it is difficult to remove biofilms from implant surfaces completely. Therefore, it is necessary to administer topical and systemic antibiotics, as PI conventional adjunctive treatment, to more thoroughly remove biofilms from the implant surfaces and microorganisms around the lesions.

The discovery of penicillin brought hope for the treatment of infectious diseases caused by pathogenic microorganisms, leading to the development of many antibiotics, with significant contributions to protecting human health ${ }^{23}$. However, the widespread use of these "traditional antibiotics" continuously gave rise to many new problems, such as drug-resistant strains. Therefore, researchers began to look for a new generation of antibacterial agents. Cefuroxime belongs to the second generation cephalosporins, the antibacterial effects against gram-negative bacteria is enhanced compared with the first generation cephalosporins. As shown in MIC and MBC tests, cefuroxime actually exerted stronger antibacterial effects against Pg and Pi compared with Pln 149, and they showed the same antibacterial effects against $S$. aureus. Researches showed that cefuroxime especially likely to develop drug resistance in S. aureus and P. Aeruginos $a^{24}$, our results showed that Pln 149 was difficult to form drug resistance. The osseointegration of the implant which is the key to the success of dental implant is based on the establishment of bone-implant surface contact. Osteoblasts originated from bone marrow stem cells, play an important role in the secretion, mineralization and synthesis of bone matrix ${ }^{25}$, Pln 149 showed 
no cytotoxicity on BMSC and low levels of drug resistance which indicated that the use of Pln 149 for a longer period of time is safe and efficient.

Recent studies have found that some cationic peptides exhibit a broad-spectrum antimicrobial activity, resulting in no drug-resistant bacteria ${ }^{26}$. Studies on bacteriocin isolated from lactic acid bacteria (LAB) have confirmed that some bacteria in this group, such as L. rhamnosus $G G$, can produce bacteriocin, significantly impacting most gram-positive and some gram-negative bacteria ${ }^{27}$. Previous studies have shown that Lactobacillus reuteri could more effectively alleviate patients' symptoms, improve the microbial environment around the implant, and exert a better therapeutic effect on $\mathrm{PI}^{28}$. The study of Jae-In Jung showed that Lactobacillus plantarum has great potential as a multifunctional oral health ingredient that inhibits biofilm formation and suppresses the alveolar bone loss associated with periodontitis ${ }^{29}$. However, the relevant studies have not indicated the substances and mechanisms involved. In the present study, Pg and Pi counts on the titanium plate decreased significantly, consistent with previous studies indicating that Pln 149 produced by probiotic Lactobacillus plantarum could positively impact PI treatment ${ }^{30}$. The antibacterial mechanism of traditional antibacterial drugs mainly includes inhibition of bacterial cell-wall biosynthesis, bacterial protein synthesis and bacterial DNA replication and repair ${ }^{31}$. However, eighty percent of bacterial infections are related to the formation of bacterial biofilm, traditional antibacterial drugs could not permeate into the bacterial biofilm. Compared with planktonic bacteria, bacterial biofilm is 10-1000 times more resistant to antibiotics, which is the main cause of current bacterial drug resistance ${ }^{32}$. Metabolic regulation between distant bacteria in biofilms may involve electrochemical communication ${ }^{33}$. Study showed that ion channels conduct long-range electrical signals within bacterial biofilm communities through spatially propagating waves of potassium. Our study showed that Pln 149 could change the sodium channels which indicated that Pln 149 could inhibited the biofilm formation by ion channel. Compared with traditional antibacterial drugs used in oral, Pln 149 exerted the strong anti-biofilm effects, low drug resistance, excellent biocompatibility, and the use of Pln 149 may provides new ideas for the treatment of peri-implantitis.

It is interesting to observe the antibacterial effect of Pln 149 on the growth of Pg and Pi; however, the implant in the oral cavity is inhabited by a highly diverse and dense population of bacteria, which form a complex ecosystem that is difficult to simulate in vitro. Therefore, studying the antibacterial effect of Pln 149 in vivo is still necessary to understand the role of Pln 149 in the PI treatment. We will provide PI patients with probiotic products to detect peri-implant micro-ecological changes using high-throughput sequencing technologies in future experiments.

In conclusion, Pln 149 could inhibit the growth of $\mathrm{Pg}$ and $\mathrm{Pi}$ in vitro, impacted the bacteria in the biofilm on titanium plates by changed the sodium channel currents, and exhibited safety and a good application value in PI treatment.

\section{Data availability}

The authors declare that all data and materials support published claims and comply with field standards.

Received: 26 May 2021; Accepted: 11 October 2021

Published online: 25 October 2021

\section{References}

1. Renvert, S., Persson, G. R., Pirih, F. Q. \& Camargo, P. M. Peri-implant health, peri-implant mucositis, and peri-implantitis: Case definitions and diagnostic considerations. J. Clin. Periodontol. 45, 2 (2018).

2. Al Deeb, M., Alsahhaf, A., Alhamoudi, N., Al-Aali, K. A. \& Abduljabbar, T. Clinical and microbiological outcomes of photodynamic and systemic antimicrobial therapy in smokers with peri-implant inflammation. Photodiag. Photodynamic. Therapy. 29, 101587 (2020).

3. Lasserre, J. F., Brecx, M. C. \& Toma, S. Oral microbes, biofilms and their role in periodontal and peri-implant diseases. Materials. 11, 1802 (2018).

4. Khan, M. U., Pirzadeh, M., Förster, C. Y., Shityakov, S. \& Shariati, M. A. Role of milk-derived antibacterial peptides in modern food biotechnology: Their synthesis, applications and future perspectives. Biomolecules 8, 110 (2018).

5. Lewis-Mikhael, A.-M., Davoodvandi, A. \& Jafarnejad, S. Effect of Lactobacillusplantarum containing probiotics on blood pressure: A systematic review and meta-analysis. Pharmacol. Res. 153, 104663 (2020).

6. Barreto-Santamaría, A. et al. Shorter antibacterial peptide having high selectivity for e. Coli membranes and low potential for inducing resistance. Microorganisms. 8, 867 (2020).

7. Kumagai, P. S. et al. Unveiling the binding and orientation of the antimicrobial peptide Plantaricin 149 in zwitterionic and negatively charged membranes. Eur. Biophys. J. 48, 621-633 (2019).

8. Topaç, T., Ağca, H., Sağlam, S., Efe, K. \& Ener, B. Comparison of Clinical Laboratory Standards Institute (CLSI) and European Committee on Antimicrobial Susceptibility Testing (EUCAST) broth microdilution methods for determining the susceptibilities of Candida isolates. Mikrobiyol. Bul. 52, 35-48 (2018).

9. Lin, X., Chen, X., Tu, Y., Wang, S. \& Chen, H. Effect of probiotic lactobacilli on the growth of streptococcus mutans and multispecies biofilms isolated from children with active caries. Med. Sci. Monit. 23, 4175 (2017).

10. Choi, E. J., Lee, S. H. \& Kim, Y. J. Quantitative real-time polymerase chain reaction for Streptococcus mutans and Streptococcus sobrinus in dental plaque samples and its association with early childhood caries. I.J. Paediat. Dentist. 19, 141-147 (2009).

11. Alonso, R., Pisa, D., Fernández-Fernández, A. M., Rábano, A. \& Carrasco, L. Fungal infection in neural tissue of patients with amyotrophic lateral sclerosis. Neurobiol. Dis. 108, 249-260 (2017).

12. Hrubanova, K. et al. Monitoring Candida parapsilosis and Staphylococcus epidermidis biofilms by a combination of scanning electron microscopy and Raman spectroscopy. Sensors. 18, 4089 (2018).

13. Ghaderi, P., Marateb, H. R. \& Safari, M.-S. Electrophysiological profiling of neocortical neural subtypes: a semi-supervised method applied to in vivo whole-cell patch-clamp data. Front. Neurosci. 12, 823 (2018).

14. Stockert, J. C., Horobin, R. W., Colombo, L. L. \& Blázquez-Castro, A. Tetrazolium salts and formazan products in cell biology: Viability assessment, fluorescence imaging, and labeling perspectives. Acta. Histochem. 120, 159-167 (2018).

15. Boehle, K. E. et al. Utilizing paper-based devices for antimicrobial-resistant bacteria detection. Angewandte. Chemie. Int. Edit. 56, 6886-6890 (2017). 
16. Ferreira, S. D., Silva, G. L. M., Cortelli, J. R., Costa, J. E. \& Costa, F. O. Prevalence and risk variables for peri-implant disease in Brazilian subjects. J. Clin. Periodontol. 33, 929-935 (2010).

17. Robitaille, N., Reed, D. N., Walters, J. D. \& Kumar, P. S. Periodontal and peri-implant diseases: Identical or fraternal infections?. Mol. Oral. Microbiol. 31, 285-301 (2016).

18. Heitz-Mayfield, L. J. A. \& Lang, N. P. Antimicrobial treatment of peri-implant diseases. Int. J. Oral Maxillofac. Implants. 19, 2 (2004).

19. Elias, C. N., Rocha, F. A., Nascimento, A. L. \& Coelho, P. G. Influence of implant shape, surface morphology, surgical technique and bone quality on the primary stability of dental implants. J. Mech. Behav. Biomed. Mater. 16, 2 (2012).

20. Ma, L., Ding, Q., Feng, X. \& Li, F. The protective effect of recombinant FomA-expressing Lactobacillus acidophilus against periodontal infection. Inflam. 36, 1160-1170 (2013).

21. Kočar, M., Seme, K. \& Hren, N. I. Characterization of the normal bacterial flora in peri-implant sulci of partially and completely edentulous patients. Int. J. Oral Maxill. Implant. 25, 2 (2010).

22. Winnett, B., Tenenbaum, H. C., Ganss, B. \& Jokstad, A. Perioperative use of non-steroidal anti-inflammatory drugs might impair dental implant osseointegration. Clin. Oral. Implant. Res. 27, e1-e7 (2016).

23. Gaynes, R. The discovery of penicillin-new insights after more than 75 years of clinical use. Emerg. Infect. Dis. 23, 849 (2017).

24. Deng, H. \& Xue, Y. X. The distribution and drug resistance analysis of haemophilus in the respiratory tract infection samples. J. Trop. Med. 48, 2 (2009).

25. Schminke, B. et al. The pathology of bone tissue during peri-implantitis. J. Dent. Res. 94, 354 (2015).

26. Lei, J. et al. The antimicrobial peptides and their potential clinical applications. Am. J. Translat. Res. 11, 3919 (2019).

27. Xu, C. et al. Purification and antimicrobial mechanism of a novel bacteriocin produced by Lactobacillus rhamnosus 1.0320. Lwt. 137, 110338 (2021).

28. Galofré, M., Palao, D., Vicario, M., Nart, J. \& Violant, D. Clinical and microbiological evaluation of the effect of Lactobacillus reuteri in the treatment of mucositis and peri-implantitis: A triple-blind randomized clinical trial. J. Periodont. Res. 53, 378-390 (2018).

29. Jung, J. I., Baek, S. M., Nguyen, T. H., Kim, J. W. \& Imm, J. Y. Effects of probiotic culture supernatant on cariogenic biofilm formation and RANKL-induced osteoclastogenesis in RAW 264.7 macrophages. Molecule. 26, 733 (2021).

30. Mongardini, C., Pilloni, A., Farina, R., Tanna, G. D. \& Zeza, B. Adjunctive efficacy of probiotics in the treatment of experimental peri-implant mucositis with mechanical and photodynamic therapy: A randomized, cross-over clinical trial. J. Clin. Periodontol. 44, 2 (2016).

31. Dai, J., Bai, M., Li, C., Cui, H. \& Lin, L. Advances in the mechanism of different antibacterial strategies based on ultrasound technique for controlling bacterial contamination in food industry. Trend. Food. Sci. Techn. 105, 211-222 (2020).

32. Jang, Y. S. \& Mosolygó, T. Inhibition of bacterial biofilm formation by phytotherapeutics with focus on overcoming antimicrobial resistance. Cur. Pharmaceut. Des. 2, 2 (2020).

33. Manna, S., Ghanty, C., Baindara, P., Barik, T. K. \& Mandal, S. M. Electrochemical communication in biofilm of bacterial community. J. Basic. Microbiol. 60, 819-827 (2020).

\section{Acknowledgements}

The research was supported by Zhejiang Medical and Health Science and Technology Project (2021432830).

\section{Author contributions}

Fuming He conceived and designed research. Tao Fu and Jiajia Xu conducted experiments. Yuedan Xu and Zhiwei Shi analyzed data. Ling Zhang and Xiaolong Lin wrote the manuscript. All authors read and approved the manuscript.

\section{Competing interests}

The authors declare no competing interests.

\section{Additional information}

Correspondence and requests for materials should be addressed to L.Z. or F.H.

Reprints and permissions information is available at www.nature.com/reprints.

Publisher's note Springer Nature remains neutral with regard to jurisdictional claims in published maps and institutional affiliations.

Open Access This article is licensed under a Creative Commons Attribution 4.0 International License, which permits use, sharing, adaptation, distribution and reproduction in any medium or format, as long as you give appropriate credit to the original author(s) and the source, provide a link to the Creative Commons licence, and indicate if changes were made. The images or other third party material in this article are included in the article's Creative Commons licence, unless indicated otherwise in a credit line to the material. If material is not included in the article's Creative Commons licence and your intended use is not permitted by statutory regulation or exceeds the permitted use, you will need to obtain permission directly from the copyright holder. To view a copy of this licence, visit http://creativecommons.org/licenses/by/4.0/.

(C) The Author(s) 2021 